\title{
European languages linked to migration from the east
}

\section{Large ancient-DNA study uncovers population that moved westwards 4,500 years ago.}

\section{Ewen Callaway}

12 February 2015

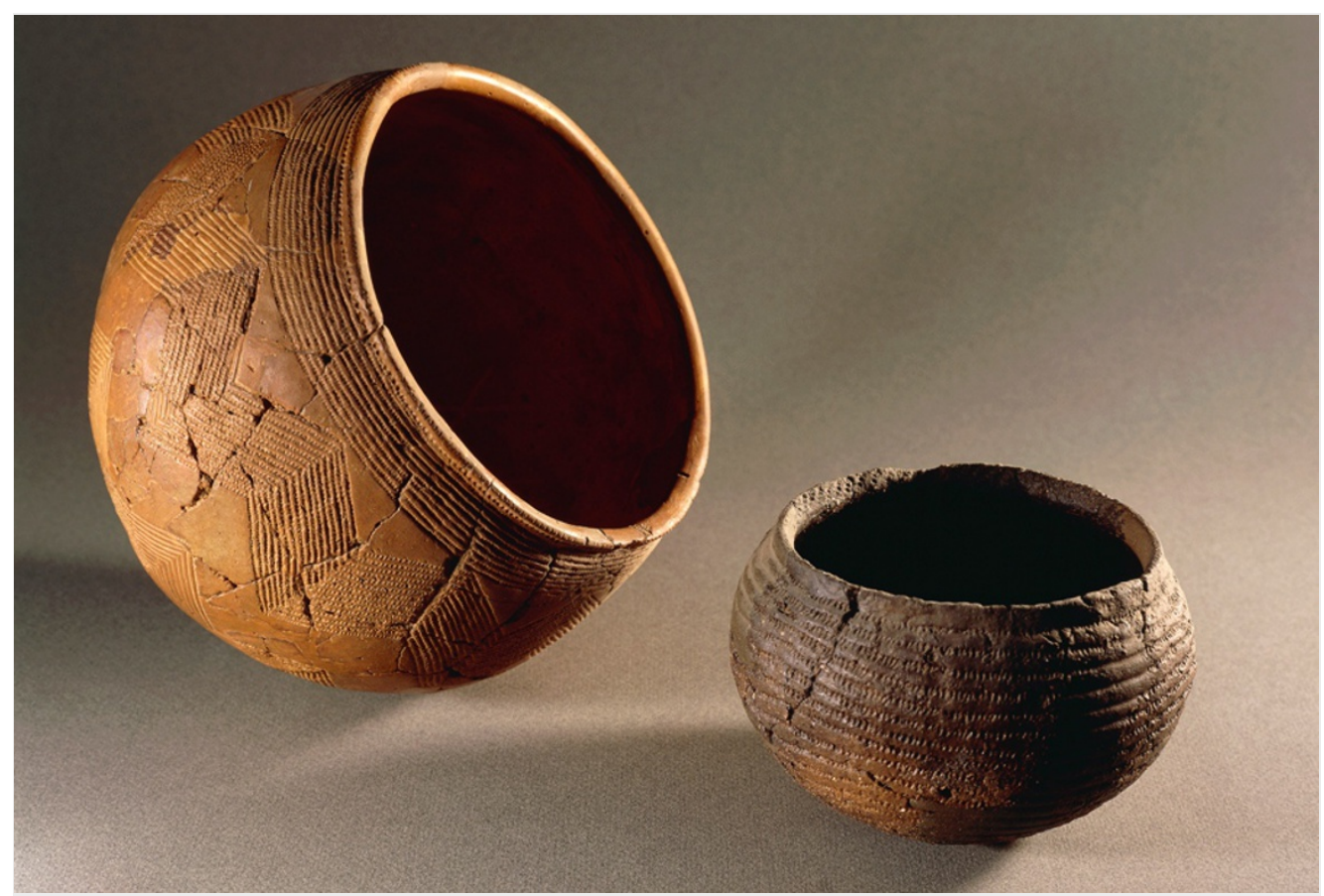

DEA/G. Dagli Orti/De Agostini/Getty

Artifacts similar to these pottery vesssels from Sweden are found across northern Europe, and give the Corded Ware culture its name. Ancient DNA suggests that the group was related to the Yamnaya people who lived in present-day Russia.

A mysterious group of humans from the east stormed western Europe 4,500 years ago - bringing with them technologies such as the wheel, as well as a language that is the forebear of many modern tongues, suggests one of the largest studies of ancient DNA yet conducted. Vestiges of these eastern émigrés exist in the genomes of nearly all contemporary Europeans, according to the authors, who analysed genome data from nearly 100 ancient Europeans ${ }^{1}$.

The first Homo sapiens to colonize Europe were hunter-gatherers who arrived from Africa, by way of the Middle East, around 45,000 years ago. (Neanderthals and other archaic human species had begun roaming the continent much earlier.) Archaeology and ancient DNA suggest that farmers from the Middle East started streaming in around 8,000 years ago, replacing the hunter-gatherers in some areas and mixing with them in others.

But last year, a study of the genomes of ancient and contemporary Europeans found echoes not only of these two waves from the Middle East, but also of an enigmatic third group that they said could be from farther east ${ }^{2}$ (see 'Ancient European genomes reveal jumbled ancestry').

\section{Ancient genes}

To further pin down the origins of this ghost lineage, a team led by David Reich, an evolutionary and population geneticist at Harvard Medical School in Boston, Massachusetts, analysed nuclear DNA from the bodies of 69 individuals who lived across Europe between 8,000 and 3,000 years ago. They also examined previously published genome data from another 25 ancient Europeans, including Ötzi, the 5,300-year-old 'ice man' who was discovered on the Italian-Austrian border.

Their analysis confirmed the arrival of Middle Eastern farmers in Europe between 8,000 and 7,000 years ago. But the team also found proof of a previously unknown migration, beginning several thousand years later. DNA recovered from steppe herders that lived in western Russia around 5,000 years ago closely matched that of 4,500-year-old individuals from Germany, who were part of a group 
known as the Corded Ware culture.

The herders, named the Yamnaya, lived in present-day Russia and Ukraine and represent "a massive migration into the heartland of Europe from its eastern periphery", Reich and his team say in a paper posted on the bioRxiv preprint server on 10 February 1. Yamnaya ancestry survives in varying degrees in the genomes of contemporary Europeans, with northern groups such as Norwegians, Scots and Lithuanians maintaining the strongest link. The geographical extent of the Yamnaya migration is not clear, nor is its nature. But Reich's team says it is possible that the eastern migrants completely replaced existing populations in Germany.

\section{Linguistic spread}

The Yamnaya, the researchers also contend, imported at least part of the Indo-European language family into Europe. The origin of these languages - which include Germanic, Slavic and Romance languages as well as many of the languages spoken on the South Asian subcontinent - is mired in controversy. Some researchers say that the tongues were spread by Middle Eastern farmers around 8,500 years ago. But Reich and his team say that their data are more consistent with the 'steppe hypothesis' favoured by other researchers, according to which herders living around the Black and Caspian Seas spread the languages around 6,000 years ago, after horse domestication and the invention of the wheel allowed them to start travelling great distances.

"It's wonderful work. It's a big leap forward in many respects," says Stephan Schiffels, a population geneticist at the Wellcome Trust Sanger Institute in Hinxton, UK, who studies ancient DNA. "We can now sequence whole populations from the past, not just single individuals."

Pontus Skoglund, a population geneticist at Harvard Medical School who works with Reich but is not a co-author of the latest study, says that the link between the Yamnaya and the Corded Ware people is a "smoking gun". "You don't need any fancy genetic profiling. It's as direct evidence as you could hope for."

Less clear is whether all Indo-European languages derive from this group, or whether just a subset do, says Paul Heggarty, a linguist at the Max Planck Institute for Evolutionary Anthropology in Leipzig, Germany. He suspects that the Yamnaya spoke a language that later developed into Slavic, Germanic and other northern European tongues, but he doubts that they imported the predecessor of southern European languages such as ancient Greek, or those of eastern Indo-European languages such as Sanskrit.

Carles Lalueza-Fox, a palaeogeneticist at the Institute of Evolutionary Biology in Barcelona, Spain, says that the study also supports the idea that the first farmers to reach Europe were a homogeneous bunch, with little genetic variation. "Things start changing with the arrival of metallurgic technologies," he says. "Then, there are dramatic population movements and turnovers, probably related to technical improvements in tools and warfare."

Nature | doi:10.1038/nature.2015.16919

\section{References}

1. Haak, W. et al. Preprint available at http://dx.doi.org/10.1101/013433 (2015).

2. Lazaridis, I. et al. Nature 513, 409-413 (2014) 